\title{
Review of the demographic pattern and outcomes of acute chemical poisoning in patients in a tertiary hospital in South-western Nigeria
}

\author{
*Adejumo O.A. ${ }^{1}$, Owolade S.S. ${ }^{1}$, Lawal O.M. ${ }^{1}$, Junaid O.A. ${ }^{1}$, Egbi O.G. ${ }^{2}$, \\ Enikuomehin A.C. ${ }^{1}$, Umufo B.A. ${ }^{1}$
}

\begin{abstract}
Introduction: Acute chemical poisoning is a public health problem especially in developing countries where there is unrestricted access to chemical products, underreporting and absence of poisoning registers. Despite its importance, there is limited information on acute poisoning among adult population in Nigeria. The study was aimed at determining the demographic pattern and short term outcomes of acute chemical poisoning in patients in a tertiary health institution in South-western Nigeria over a 2 year period.
\end{abstract}

Methodology: Records of cases of acute chemical poisoning over a 2-year period were retrieved and the following information extracted: socio-demographic data of patient, type of substance ingested, type of poisoning, reason for poisoning, intervention, and outcome of treatment.

Results: There were 58 patients with a M:F ratio of 1:1.1. The mean age was $28.53 \pm 13.47$ years. The most commonly ingested chemical was organophosphate seen in 31(53.4\%). Poisoning was deliberate in 43 (74.1\%); 36 patients $(62.1 \%)$ had atropine; 16 patients $(27.6 \%)$ had gastric lavage; one patient $(1.7 \%)$ was dialyzed and 2 patients $(3.4 \%$ ) were admitted into ICU. Mortality rate was $8.6 \%$.

Conclusion: Deliberate acute chemical poisoning was common in young adults. Organophosphate is the most commonly ingested chemical. Government should enforce laws that that would restrict access to potentially harmful chemicals.

Keywords: Acute Chemical Poisoning, Outcome, Demographic Pattern

\footnotetext{
*Corresponding author

Adejumo. O.A.

ORCID-NO: http://orcid.org/0000-0002-0111-2843

Email: oluseyiadejumo2017@gmail.com

${ }^{1}$ Department of Internal Medicine, University of Medical Sciences, Ondo, Nigeria

${ }^{2}$ Department of Internal Medicine, Niger Delta University, Bayelsa State, Nigeria
} 


\title{
Schéma et résultats à court terme d'une intoxication chimique aiguë dans un hôpital tertiaire du sud-ouest du Nigéria
}

\author{
*Adejumo O.A. ${ }^{1}$, Owolade S.S. ${ }^{1}$, Lawal O.M. ${ }^{1}$, Junaid O.A. ${ }^{1}$, Egbi O.G. ${ }^{2}$, \\ Enikuomehin A.C. ${ }^{1}$, Umufo B.A. ${ }^{1}$
}

\begin{abstract}
Résumé
Introduction : Les intoxications chimiques aiguës sont un problème de santé publique en particulier dans les pays en développement où il existe un accès illimité aux produits chimiques, une sous-déclaration et l'absence de registres des intoxications. Malgré son importance, il existe peu d'informations sur les intoxications aiguës parmi la population adulte au Nigéria.
\end{abstract}

Objectif de l'étude: Déterminer le schéma démographique et les résultats à court terme des intoxications chimiques aiguës chez les patients d'un établissement de santé tertiaire du sud-ouest du Nigéria sur une période de 2 ans.

Méthode de l'étude : Des dossiers de cas d'intoxication chimique aiguë sur une période de 2 ans ont été récupérés et les informations suivantes extraites : données sociodémographiques du patient, type de substance ingérée, type d'intoxication, raison de l'intoxication, intervention et résultat du traitement.

Résultat de l'étude : Il y avait 58 patients avec un rapport $M: F$ de 1:1,1. L'âge moyen était de 28,53 \pm 13,47 ans. Le produit chimique le plus couramment ingéré était l'organophosphate vuswzsw3 dans 31 $(53,4 \%)$. L'empoisonnement était délibéré dans 43 (74,1\%); 36 patients (62,1\%) avaient de l'atropine; 16 patients $(27,6 \%)$ ont eu un lavage gastrique ; un patient $(1,7 \%)$ a été dialysé et 2 patients $(3,4 \%)$ ont été admis en réanimation. Le taux de mortalité était de $8,6 \%$.

Conclusion : Les intoxications chimiques aiguës délibérées étaient fréquentes chez les jeunes adultes. L'organophosphate est le produit chimique le plus couramment ingéré. Le gouvernement devrait appliquer des lois qui restreindraient l'accès aux produits chimiques potentiellement nocifs.

Mots-clés : Intoxication chimique aiguë, résultat, modèle démographique

\author{
*Corresponding author \\ Adejumo. O.A. \\ ORCID-NO: http://orcid.org/0000-0002-0111-2843 \\ Email: oluseyiadejumo2017@gmail.com

\footnotetext{
${ }^{1}$ Department of Internal Medicine, University of Medical Sciences, Ondo, Nigeria

${ }^{2}$ Department of Internal Medicine, Niger Delta University, Bayelsa State, Nigeria
} 


\section{INTRODUCTION:}

A poison is a substance that causes harm to the body and endangers life through its local and systemic effect (1). The time of onset of these harmful effects varies from almost immediately to several hours after exposure to the poison. Acute poisoning may be intentional (deliberate) or unintentional (accidental). Intentional poisoning occurs when a person takes a substance with the intention of causing self-harm or suicide while unintentional poisoning occurs if a person takes a substance without the aim of causing harm. Unintentional poisoning may occur due to error in judgment, carelessness or negligence. When it is impossible to differentiate between deliberate and accidental poisoning, then the poisoning is considered undetermined in intent.

Acute poisoning is becoming a major public health problem. The World Health Organization's (WHO) report showed that in 2012, about 193,460 died globally from unintentional poisoning with majority occurring in low and middle income countries (2). Also, about one million people die yearly from suicide and chemical poisoning account for a significant number of these deaths (2). There are also concerns that the current figures, though staggering, are still largely under-reported.

Acute poisoning has also become a great concern in Nigeria because it is a major method of committing suicide which has been on the increase recently $(3,4)$. Furthermore, it has devastating effect on the economy because majority of the affected individuals are young adults who are in their economically productive years. A major contributor to the rising incidence of acute chemical poisoning is the unrestricted access to a wide range of agrochemicals for agricultural practices especially in this era of diversification of the economy. This is further compounded by lack of laws regulating the use of these chemicals.

In Nigeria, there is paucity of information on acute chemical poisoning in adults. There is also no official poisoning register in Nigeria. Majority of the studies on poisoning were conducted among paediatric population. This study reviewed the pattern and short term outcomes of acute chemical poisoning in University of Medical Sciences Teaching Hospital, Ondo State, Nigeria over a 2 year period. The findings from the study will help to fill part of the existing knowledge gaps in the areas of demographic pattern and short term outcomes of acute poisoning in adults.

\section{METHODOLOGY}

This was a descriptive, retrospective study that was conducted in University of Medical Sciences Teaching Hospital, Ondo City, Nigeria. The study covered a period of 24 months between July 2018 and June 2020. The hospital is a state government-owned tertiary and referral health facility. Referrals are received from both public and private health facilities within and outside the state.

All the case notes of patients that were managed for acute chemical poisoning were retrieved from the hospital's Health Information Management Department. Inclusion criteria were patients who were managed for acute chemical poisoning during the review period. Cases notes of patients who had other forms of poisonings such as snake bites were excluded.

A proforma was used to extract information which included socio-demographic data, type of substance ingested, type of poisoning and reason for poisoning, medical intervention and outcome of treatment.

Ethical consideration: Ethical approval for the study was obtained from the Ethics and Research Committee of University of Medical Sciences, Ondo. All proformas were coded (without names) and confidentiality of information was ensured throughout the study.

\section{Data Analysis}

Data entry and analysis was done using IBM Statistical Package for Social Science version 21. Categorical variables were expressed as frequencies and proportions. Continuous data were presented as mean and standard deviation. Quantitative data were displayed in tables and charts.

\section{RESULTS}

There were fifty-eight patients comprising of $28(48.3 \%)$ males and $30(51.7 \%)$ females in this study with a mean age of $28.53 \pm 13.47$ years. Twenty $(34.5 \%)$ were between age group 21-30 years and 19(32.8\%) were below 20 years. More than half $(56.9 \%)$ were single, $21(36.2 \%)$ were students and $20(34.5 \%)$ were traders. Majority (94.8\%) of the participants were Yoruba. Poisoning was deliberate in $43(74.1 \%)$ patients. Twenty-nine $(50 \%)$ presented within 2 hours of ingestion of the poison as seen in table 1 .

The commonly ingested chemicals were organophosphates in 31(53.4\%), detergent and disinfectants in 7(12.1\%). Reasons for deliberate 
ingestion of poison were conflict in $16(37.2 \%)$, suicidal ideation in $6(14 \%)$ and financial challenge in $5(11.6 \%)$ as seen in table 3 . With regard to medical intervention, atropine was administered in 36 patients $(62.1 \%)$, gastric lavage in $16(27.6 \%)$, one $(1.7 \%)$ was dialyzed and $2(3.4 \%)$ were admitted into intensive care unit (ICU) as seen in figure 1 . Short term outcome of treatment showed that $28(48.3 \%)$ were discharged, 17(29.3\%) discharged against medical advice (DAMA) while 5(8.6\%) died as seen in figure 2.

\section{DISCUSSION}

The patients in our study were generally young with a greater proportion between the age range of 20 and 30 years which is similar to reports of some previous studies (5-11). This finding suggests that acute chemical poisoning most commonly affects the younger population of the society. This has implications on the economy because they constitute a significant part of the work force contributing to socioeconomic growth and development of the country.

In our study, acute chemical poisoning was slightly more common in females compared to males. Some studies have similarly reported female preponderance in acute chemical poisoning $(8,10,12,13)$, although male preponderance has also been reported in some others studies $(6,11,14)$.

A greater proportion of our patients (61\%) were single. There is the possibility that this group may be at a higher risk of deliberate poisoning because of lack of spousal social support when faced with challenges. However, the finding in our study is at variance with that of Gargi et al(6) who reported a higher prevalence of acute chemical poisoning among married individuals. The reason for this is not obvious, but may be related to socio-cultural differences across countries. For instance our study was done in Nigeria, while that of Gargi et al(6) was done in India. About $60 \%$ of those who were managed for acute chemical poisoning were employed. There is possibility that inability to cope with the pressure and challenges encountered in the workplace might have contributed to their decision to deliberately ingest poisoning in order to terminate their lives.

Majority of the patients $(81.1 \%)$ were managed for deliberate poisoning which is comparable to $76.5 \%$ reported by Gargi et al (6), but lower than $63.8 \%$ reported by Raizada et a 1(5). The finding of our study is in keeping with previous studies that showed that deliberate poisoning was more prevalent than accidental poisoning in adults $(6,15)$. However, Hu et al (15) reported that accidental poisoning was the predominant type in their study. This may be due to the fact that their study was conducted among an elderly population. The elderly are more prone to ocular problems such as refractory errors, cataract and amblyopia which may impair their vision, (16) thereby predisposing them to accidental ingestion of drugs and chemicals.

The pattern of poisoning observed in our study is also different from what was reported in various paediatric population which were majorly accidental (17-19). The relatively high proportion of deliberate poisoning reported in this present study may also be a reflection of the rising incidence of suicide in Nigeria (20). This is supported by Uchendu et al (3) who reported that deliberate poisoning is a common method of committing suicide in Nigeria.

Organosphosphate was the major chemical ingested in our study corroborating reports of some studies $(8-12,21)$. However, our finding is different from reports by $\mathrm{Hu}$ et al (15) and Matthew et al (22). While $\mathrm{Hu}$ et al (15) reported medications as the most common cause of poisoning in their study, Matthew et al(21) found out that corrosives were the most commonly ingested poison. Our finding of organophosphate as the most common chemical ingested may be due to the fact that agrochemicals are commonly used and readily available for purchase in developing countries including Nigeria.

Only $3.5 \%$ of the patients in our study were admitted into ICU which is lower than $10.2 \%$ reported by Sulaj et al (13). However, the study by Sulaj et al (13) involved all patients with acute poisoning, unlike our study that only included acute chemical poisoning. The low admission rate into ICU may be due to the fact that majority presented early and do not have severe form of poisoning. Atropine was used in the management of high proportion of our patients which is similar to report by Adinew et al (8). This may be explained by the fact that it is the readily available antidote for organophosphate poisoning which was common in our study.

Mortality rate in our study was $8.6 \%$ which is comparable with $8.3 \%$ and $9.6 \%$ reported by Sharma et al (14) and Hu et al (15) respectively. This is lower than $54.2 \%$ reported by Sulaj et al (13) who studied patients admitted into ICU on account of poisoning. This is not surprising because patients who required ICU admission following poisoning are more likely to be 
severely ill and requiring multiple organ support.

The proportion of those that discharged against medical advice (DAMA) in this study was $29.3 \%$. This is relatively high compared to the overall prevalence of $3.2 \%$ that was reported by Akinbodewa et al (23) in a study conducted earlier in the same hospital. The high rate of DAMA may be due to the likely stigmatization of patients who attempt suicide and a reflection of the worsening economic situation of the country especially as it relates to health care. Furthermore in Nigeria, the culture and the two major religions (Christianity and Islam) do not support suicide. Attempted suicide is a criminal offence according to the law of the Federal Republic of Nigeria that is punishable under law (24). This may partly account for why families usually request for discharge as soon as possible even when the patients have not fully recovered.

\section{CONCLUSION}

The study found that acute chemical poisoning is becoming a more common medical emergency presentation among young Nigerian population and is predominantly deliberate. The most common chemical ingested was organophosphate.

Recommendations: Government should enforce laws that would restrict access to organophosphate and other potentially harmful chemical and provide social support for the youth who tend to be more vulnerable. The public should be regularly educated on the impact of chemical poisoning and proper labeling of chemical substances. Regular campaigns against suicide should be conducted and counseling clinics where people can discuss with psychologists and chart a path out of their problems should be created.

\section{Competing Interest: None}

Acknowledgment: We acknowledge the medical students of University of Medical Sciences who assisted us in data acquisition.

\section{REFERENCES}

1. Jesslin J, Adepu R, Churi S. Assessment of prevalence and mortality incidences due to poisoning in a south Indian tertiary care teaching hospital. Indian J Pharm Sci. 2010;72(5):587591

2. Poisoning Prevention and Management. Available at https://www.who.int/ipcs/ poisons/en/ Accessed on 25th February, 2021

3. Uchendu OJ, Ijomone EA, Nwachokor NF.
Suicide in Warri, Delta State, Nigeria: An autopsy study. Annals of Tropical Pathology 2019;10(1):16-19

4. Nwosu SO, Odesanmi WO. Pattern of Suicides in Ile-Ife, Nigeria. West Afr J Med 2001;20(3):259-62

5. Raizada A, Kalra OP, Khaira A, Yadav A. Profile of hospital admissions following acute poisoning from a major teaching hospital in North India. Trop Doct. 2012;42(2):70-73

6. Gargi J, Rai H, Chanana A, Rai G, Sharma G, Bagga IJ. Current trend of poisoning-a hospital profile. J Indian Med Assoc. 2006;104(2):72-83

7. Ramesha KN, Rao KB, Kumar GS. Pattern and outcome of acute poisoning cases in a tertiary care hospital in Karnataka, India. Indian J Crit Care Med. 2009;13(3):152-155.

8. Adinew GM, Woredekal AT, DeVos EL, Birru EM, Abdulwahib MB. Poisoning cases and their management in emergency centres of government hospitals in northwest Ethiopia. African Journal of Emergency Medicine 2017;7(2):74-78.

9. Chelkeba L, Mulatu A, Feyissa D, Bekele F, Tesfaye BT. Patterns and epidemiology of acute poisoning in Ethiopia: systematic review of observational studies. Archives of public health. $2018 ; 76(1)$. Ava i lable from https://doi.org/10.1186/s13690-018-0275-3

10. Okumu MO, Patel MN, Bhogayata FR, Olweny IA, Ochola FO, Onono JO. Acute poisonings at a regional referral hospital in western Kenya. Tropical Medicine and Infectious Disease. 2018 ;3(3):96. doi: 10.3390/tropicalmed3030096

11. Nyamu DG, Maitai CK, Mecca LW, Mwangangi EM. Trends of acute poisoning cases occurring at the Kenyatta National Hospital, Nairobi, Kenya. East and Central African Journal of Pharmaceutical Sciences. 2012;15(2):29-34.

12. Zang J, Xiang P, Zhuo X. Acute Poisoning Types and Prevalence in Shanghai, China, from January 2010 to August 2011.World J Emerg Med. 2010;1(2):154-156

13. Sulaj Z, Prifti E, Demiraj A, Strakosha A. Early Clinical Outcome of Acute Poisoning Cases Treated in Intensive Care Unit. Med Arch. 2015;69(6):400-404

14. Sharma R, Neelanjana NR, Panwar N. Mortality and Morbidity associated with acute poisoning cases in north-east India: A retrospective study. Journal of Family Med Prim Care 2019;8(6):2068-2072.

15. Hu YH, Chou HL, Lu WH, Huang HH, Yang CC, Yen DH et al. Features and prognostic factors for elderly with acute poisoning in the emergency department. Journal of the Chinese Medical Association. 2010;73(2):78-87.

16. Khalaj M, Barikani A, Ghasemi H. Eye disorders in old people. Global Journal of Health Science. 2013;5(1):79-86

17. Sahin S, Carman KB, Dinleyici EC. Acute poisoning in children; data of a pediatric 
emergency unit. Iranian Journal of Pediatrics. 2011;21(4):479-484

18. Edelu BO, Odetunde OI, Eke CB, Uwaezuoke NA, Oguonu T. Accidental Childhood Poisoning in Enugu, South-East, Nigeria. Annals of Medical and Health Sciences research. 2016;6(3):168-71.

19. Oba-Daini OO, Ogunlesi TA, Adekanmbi AF, Akodu SO. Childhood poisoning in Sagamu, Southwest, Nigeria. Nigerian Journal of Paediatrics. 2020;47(1):1-5

20. World Health Organization. Suicide in the world: global health estimates. Geneva: World Health Organization, 2019b: 1-33. Accessed on 10th July, 2021.

21. Azab SM, Hirshon JM, Hayes BD, El-Setouhy M, Smith GS, Sakr ML et al. Epidemiology of acute poisoning in children presenting to the poisoning treatment center at Ain Shams University in Cairo, Egypt, 2009-2013.Clin Toxicol(Phila). 2016; 54(1): 20-26.

22. Mathew R, Jamshed N, Aggarwal P, Patel S, Pandey RM. Profile of acute poisoning cases and their outcome in a teaching hospital of north India. J Family Med Prim care. 2019;8(12):3935-3939

23. Akinbodewa AA, Adejumo OA, Adejumo OA, Adebayo FY, Akinbodewa GO, Alli EO, Ben et al. Evaluation of administration of discharge against medical advice: Ethico-legal considerations. Nigerian Postgrad Med J 2016;23(3):141-145

24. Section 327 Criminal Code Act. Accessed on 1 July, 2021.

\section{How to cite this article:}

Review of the demographic pattern and outcomes of acute chemical poisoning in patients in a tertiary hospital in South-western Nigeria by Adejumo OA., Owolade SS., Lawal OM., Junaid OA., Egbi OG., Enikuomehin AC. , Umufo BA. Research Journal of Health Sciences, 2021, 9(4):359-367 
Table 1: Characteristics of Study Population $(\mathrm{N}=58)$

\begin{tabular}{|c|c|}
\hline Characteristics & n (\%) \\
\hline \multicolumn{2}{|l|}{ Gender } \\
\hline Male & $28(48.3)$ \\
\hline Female & $30(51.7)$ \\
\hline Mean Age & $28.53 \pm 13.47$ \\
\hline \multicolumn{2}{|l|}{ Age group } \\
\hline$<20$ years & $19(32.8)$ \\
\hline 21-30years & $20(34.5)$ \\
\hline 31-40years & $10(17.2)$ \\
\hline 41-50years & $5(8.6)$ \\
\hline 51-60years & $3(5.2)$ \\
\hline$>60$ years & $1(1.7)$ \\
\hline \multicolumn{2}{|l|}{ Occupation } \\
\hline Student & $21(36.2)$ \\
\hline Trader & $20(34.5)$ \\
\hline Farmer & $3(5.2)$ \\
\hline Civil servant & $2(3.4)$ \\
\hline Housewife & $1(1.7)$ \\
\hline Not stated & $11(19.0)$ \\
\hline \multicolumn{2}{|l|}{ Tribe } \\
\hline Yoruba & $55(94.8)$ \\
\hline Others & $1(5.2)$ \\
\hline \multicolumn{2}{|l|}{ Marital status } \\
\hline Single & $33(56.9)$ \\
\hline Married & $20(34.5)$ \\
\hline Divorced & $1(1.7)$ \\
\hline Not stated & $4(6.9)$ \\
\hline \multicolumn{2}{|c|}{ Types of Poisoning } \\
\hline Accidental & $10(17.0)$ \\
\hline Deliberate & $43(74.0)$ \\
\hline Not Stated & $5(9.0)$ \\
\hline \multicolumn{2}{|c|}{$\begin{array}{l}\text { Duration of Poisoning } \\
\text { before Presentation }\end{array}$} \\
\hline$<1$ hour & $10(17.2)$ \\
\hline $1-2$ hour & $19(32.8)$ \\
\hline$=2$ hours & $21(36.2)$ \\
\hline Not Stated & $8(13.8)$ \\
\hline
\end{tabular}


Table 2: Type of Poison Ingested $(\mathrm{N}=58)$

\begin{tabular}{ll}
\hline Nature of substance ingested & $\mathbf{n ~ ( \% )}$ \\
\hline Organophosphates & $31(53.4)$ \\
Detergent and disinfectants & $7(12.1)$ \\
Organochlorine & $5(8.6)$ \\
Battery acid & $4(6.9)$ \\
Cement & $3(5.2)$ \\
Rat poison & $2(3.4)$ \\
Caustic soda & $2(3.4)$ \\
Calcium carbide & $1(1.7)$ \\
Soap and cream & $1(1.7)$ \\
Battery acid and rat poison & $1(1.7)$ \\
Loperamide and metronidazole & $1(1.7)$ \\
\hline
\end{tabular}

Table 3: Reasons for Deliberate Ingestion of Poison $(\mathrm{N}=43)$

\begin{tabular}{ll}
\hline Reasons for ingestion & $\mathbf{n ~ ( \% )}$ \\
\hline Conflict & $16(37.2)$ \\
Suicidal Ideation & $6(14.0)$ \\
Financial problems & $5(11.6)$ \\
Frustration & $2(4.7)$ \\
Threat & $2(4.7)$ \\
Wrongful accusation & $2(4.7)$ \\
Forced & $1(1.7)$ \\
Not stated & $9(32.8)$ \\
\hline
\end{tabular}

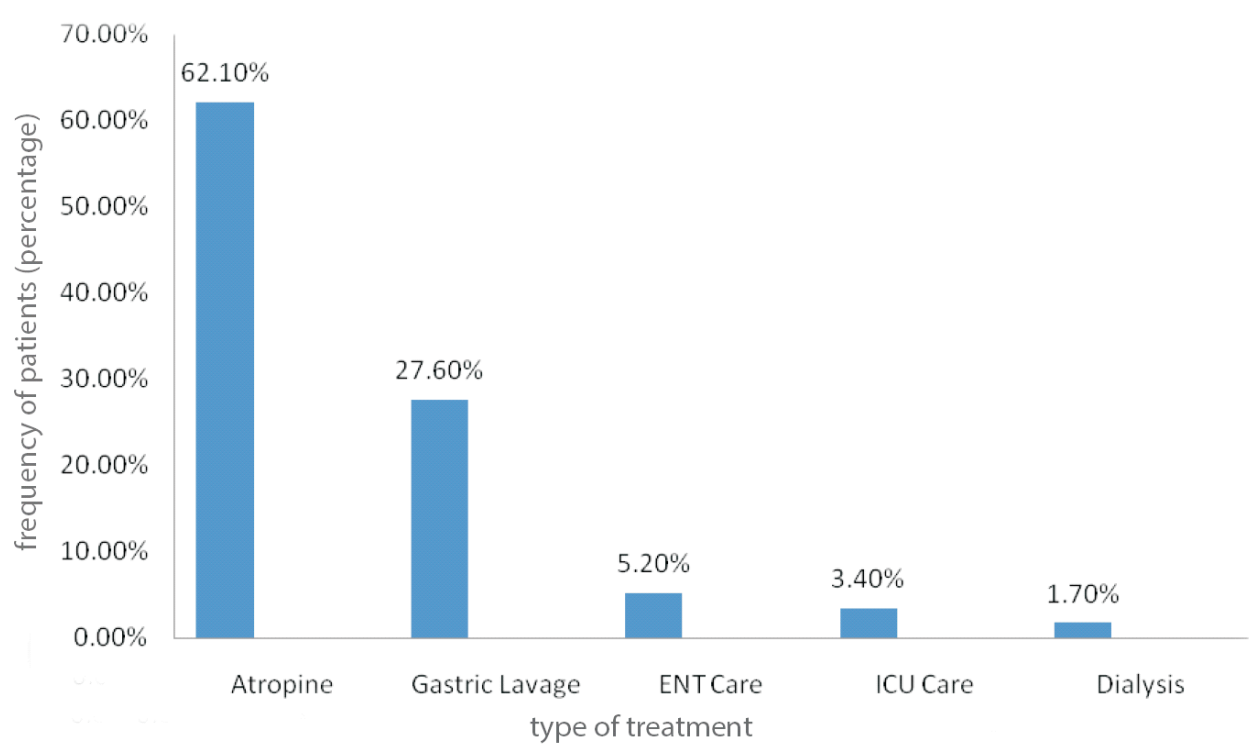

Figure 1: Treatment of Acute Poisoning 


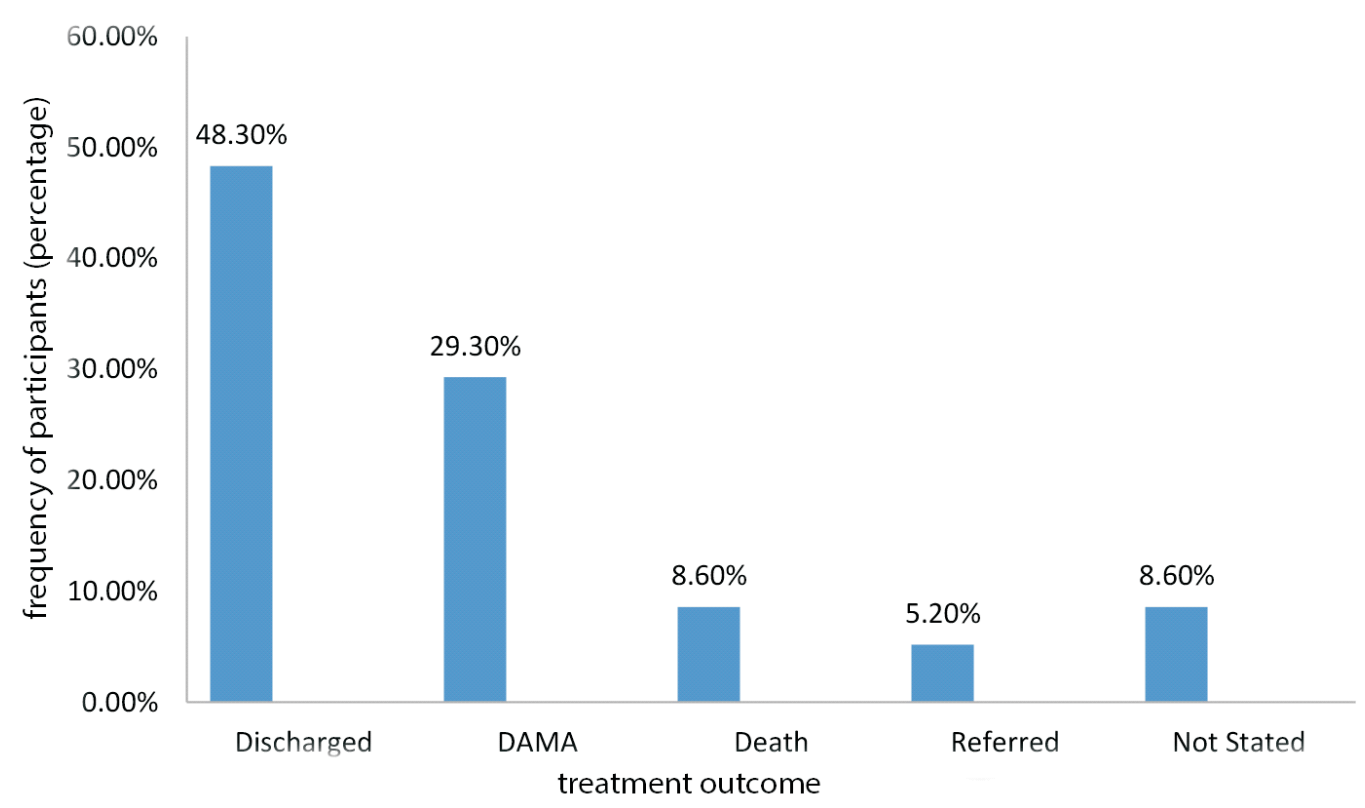

Figure 2: Outcomes of Patients with Acute Chemical Poisoning 